\title{
Peramalan Inflasi Indonesia dengan Seasonal Auto Regressive Integrated Moving Average
}

\author{
${ }^{1}$ Gagah Lanang Ramadhan*, ${ }^{2}$ Dewi Agushinta R., ${ }^{3}$ Herry Sussanto \\ ${ }^{1}$ Magister Manajemen Sistem Informasi, Perangkat Lunak Sistem Informasi \\ Program Pascasarjana Magister Sistem Informasi \\ ${ }^{2}$ Sistem Informasi, Fakultas Ilmu Komputer dan Teknologi Informasi \\ ${ }^{3}$ Manajemen Keuangan Program Diploma Bisnis Kewirausahaan \\ Universitas Gunadarma \\ *e-mail: gagahlanang98@gmail.com
}

(received: 29 Maret 2021, revised: 24 Juli 2021, accepted: 5 September 2021)

\begin{abstract}
Abstrak
Inflasi adalah satu permasalahan yang dihadapi oleh banyak negara berkembang. Salah satunya adalah negara Indonesia yang memiliki penduduk besar sehingga tingkat konsumtif pun tinggi. Dalam menjaga kestabilan ekonomi agar tidak terjadi lonjakan inflasi yang tinggi maka perlu ada yang mengaturnya. Bank Indonesia memiliki peranan yang penting dalam menjaga kestabilan ekonomi negara, dengan cara menjaga inflasi yang terjadi. Bank Indonesia sendiri memiliki kebijakan moneter yang mengatur pergerakan ekonomi dalam menjaga kestabilan inflasi Indonesia. Inflasi target merupakan metode yang digunakan Bank Indonesia untuk menjaga kestabilan ekonomi. Data mining dan machine learning merupakan satu kemajuan konsep teknologi saat ini yang dapat memrediksi atau meramalkan. Metode Time Series merupakan satu metode peramalan yang dapat digunakan dengan mempertimbangkan nilai inflasi yang akan datang. Time Series adalah metode untuk melakukan peramalan pada interval waktu tertentu. Model Auto Regressive Integrated Moving Average (ARIMA) merupakan tool dalam peramalan dengan data time series sebagai landasan dalam peramalan. Penelitian menggunakan model Seasonal-ARIMA (SARIMA) karena data yang digunakan membentuk pola musiman yang ditunjukkan pada Plot ACF dan PACF. Model SARIMA yang didapatkan dari penelitian adalah $(0,0,1),(2,1,0) 12$ dengan nilai AIC 564.393 dan Nilai MAPE pada penelitian ini sebesar 4.67426.
\end{abstract}

Kata kunci: ARIMA, data mining, inflasi, seasonal, time series

\begin{abstract}
Inflation is a problem faced by many developing countries. One of them is the country of Indonesia which has a large population so that the level of consumption is high. In maintaining economic stability so as not to cause a high spike in inflation, someone needs to regulate it. Bank Indonesia has an important role in maintaining the stability of the country's economy, by controlling inflation. Bank Indonesia itself has a monetary policy that regulates economic movements in maintaining the stability of Indonesian inflation. Target inflation is a method used by Bank Indonesia to maintain economic stability. Data mining and machine learning are advances in current technological concepts that can predict or predict. The Time Series method is a method of forecasting that can be used by considering the value of future inflation. Time Series is a method for forecasting at certain time intervals. The Auto-Regressive Integrated Moving Average (ARIMA) model is a tool in forecasting with time-series data as the basis for forecasting. The study used the Seasonal-ARIMA (SARIMA) model because the data used formed a seasonal pattern shown in the ACF and PACF plots. The SARIMA model obtained from the study is $(0,0,1),(2,1,0) 12$ with an AIC value of 564,393 and a MAPE value in this study of 4.67426..
\end{abstract}

Keywords: ARIMA, data mining, inflation, seasonal, time series 


\section{Pendahuluan}

Indonesia merupakan negara berkembang yang memiliki jumlah penduduk yang banyak, dengan penduduk yang padat Indonesia juga menjadi negara konsumtif dan produktif yang besar. Dalam pergerakan ekonomi Indonesia pemerintah harus mengaturnya agar tidak terjadinya lonjakan harga yang tinggi. Pertumbuhan ekonomi adalah kegiatan dalam perekonomian yang menyebabkan barang dan jasa yang diproduksi dalam masyarakat. Pertumbuhan ekonomi menunjukkan peningkatan dalam produksi barang maupun jasa dalam suatu perekonomian [1]. Dalam mengatur laju ekonomi Indonesia diatur oleh bank sentral yaitu Bank Indonesia. Bank Indonesia memiliki tugas utama yaitu mengatur jalananya inflasi di Indonesia. Dalam mengatur nya bank Indonesia memiliki kebijakan moneter, dalam mengatur laju perekonomian yang dilakukan bank indonesia menjaga agar tidak terjadi lonjakan inflasi yang tinggi.

Bank Indonesia menggunakan inflasi target agar dapat mengatur laju ekonomi negara Bank sentral yang menggunakan inflation targeting harus memiliki peraturan perundang-undangan kelembagaan yang dikombinasikan dengan perbuatan nyata yang memungkinkan mereka mencapai target mengingat kebijakan moneter memiliki efek nyata yang netral dalam jangka panjang [2]. Inflasi adalah salah satu masalah yang harus dihadapi agar negara tetap stabil. Inflasi dalam sejarah perekonomian Indonesia sudah menjadi masalah yang terus dihadapi dari pemerintahan ke pemerintahan berikutnya[3]. Para pengamat ekonomi menggunakan istilah inflasi untuk menggambarkan situasi di mana tingkat harga ekonomi secara keseluruhan sedang naik [4]. Tingkat pertumbuhan inflasi sangat berdampak bagi masyarakat jika inflasi telampau tinggi menandakan bahwa harga di pasaran tinggi. Kestabilan inflasi menjadi sangat penting karena berkaitan dengan pertumbuhan ekonomi yang akan berdampak pada peningkatan kesejahteraan masyarakat [5]. Inflasi menjadi indikator gambaran umum tentang perkembangan harga [6]. Inflasi bisa dikatakan sebagai pengalaman negara yang unik dan masalah lokal [7]. Beberapa penelitian menunjukkan bahwa mengadopsi inflation targeting (TI) di negara berkembang dan maju dapat meningkatkan kinerja makro ekonomi [2]. Secara sederhana inflasi diartikan sebagai meningkatnya harga-harga secara umum dan terus menerus [8].

Dalam melakukan penargetan inflasi dibutuhkan sebuah sistem yang dibantu oleh data mining. Data mining adalah teknik untuk menelusuri data kemudian membuat model yang digunakan untuk mencari pola data lain yang tidak berada dalam basis data yang disimpan. Metode-metode data mining, antara lain Association, Forecasting (peramalan), Clustering, Classification, Sequential Pattern Mining, Deviation Analysis, dan Regression. Data mining sebagai bagian machine learning dapat digunakan untuk mengatasi inflasi yang terjadi di Indonesia. Dalam penerapan data mining ini menggunakan data histori yang sudah ada dan akan dilakukan peramalan(Forecasting).

Penelitian yang dilakukan memiliki tujuan menentukan target inflasi pada masa mendatang menggunakan metode peramalan yang menggunakan metode Auto Regressive Integrated Moving Average (ARIMA). Pendekatan ARIMA (disebut Box Jenkins) ini mengacu pada literatur deret waktu (time series), telah diterapkan secara luas dalam analisis deret waktu univariat dan multivariat di berbagai bidang seperti pariwisata, kejahatan, bisnis dan sosiologi [9]. Dengan menggunakan model peramalan akan memberikan nilai inflasi dari tahun 2020 hingga tahun November 2022. Penentuan model terbaik menggunakan beberapa indikator antara lain AIC, RMSE, dan MSE. Penelitian ini diharapkan menjadi salah satu referensi Bank Indonesia sebagai metode mengatasi target inflasi di Indonesia sehingga terhindar dari hiperinflasi di Indonesia.

\section{Tinjauan Literatur}

Penelitian yang dilakukan dengan menggunakan model ARIMA banyak dilakukan untuk peramalan dalam jangka waktu tertentu seperti yang dilakukan oleh Geetha dan Nasira (2016) dalam melakukan penelitiannya dalam pemilihan model menggunakan model indikator Mean Absolute Deviation (MAD), Mean Squared Error (MSE), Mean Absolute Percent Error (MAPE) dan Root Mean Squared Error (RMSE). Nilai error pada indikator yang dipakai dipilih yang bernilai paling kecil dengan nilai RMSE $=0,464$ dan MAPE $=340.494$. Penelitian lainnya seperti Fattah, dkk (2018) menggunakan ARIMA untuk melihat kebutuhan konsumen kedepannya dengan model ARIMA (1, 0, 1). Pada penelitian inflasi yang dilakukan oleh Suparti, dkk (2019) pada sektor transportasi, komunikasi, dan jasa mendapatkan hasil bahwa pada tahun penelitian yang didapat adalah nilai inflasi 
naik sebanyak empat kali pada tahun 2009, mengalami penurunan sebesar $10 \%$ bahan bakar. Perubahan kedua terjadi pada tanggal 22 Juni 2013 meningkat $44 \%$ dari harga sebelumnya. Perubahan ketiga pada 18 November 2014 mengalami peningkatan sebesar $31 \%$ dari harga sebelumnya. Kemudian pada 1 Januari 2015 mengalami penurunan sebesar 11,8 \%. Dalam penelitian yang dilakukan oleh Delima \& Lumintac (2019), penelitian yang berfokus pada inflasi yang ada di negara Filipina menggunakan data Time Series. Model yang digunakan adalah ARIMA (7, 0, 0). Model tersebut dipilih berdasarkan nilai indikator seperti RSME, MAE, dan MAPE. Hasil yang didapatkan adalah bahwa akan terjadi inflasi sebesar $7 \%$ dari tahun 2018-2022. Berikut ini adalah literatur yang berhubungan dalam penelitian menggunakan model ARIMA.

Time Series merupakan kejadian yang terjadi pada runtut waktu tertentu secara beruntut. Data time series merupakan serangkaian pengamatan yang terurut berdasarkan waktu dengan jarak yang sama [10]. Dalam time series memiliki beberapa bagian seperti pola tren, siklis dan musiman. Data dalam runtut waktu tertentu yang digunakan sebagai dasar pengambilan keputusan seperti peramalan [11]. Dalam penelitian yang dilakukan menggunakan times series dapat menggunakan metode Auto Regressive Integrated Moving Average (ARIMA), model ini menggunakan peramalan berbasis histori waktu pada kurun waktu tertentu. Pada pembentukan model ARIMA dapat dipisahkan menjadi beberapa bagian seperti Auto Regressive (AR) dan Moving Average (MA). Model ARIMA membagi pola deret waktu menjadi tiga komponen, (1) komponen autoregresif (p), (2) komponen pembeda (d), dan (3) komponen rata-rata bergerak (q) [4]. Perumusan ARIMA dapat dilihat seperti berikut :

a) Auto Regressive (AR)

$$
x_{t}=\mu^{s}+\emptyset_{1} X_{t-1}+\emptyset_{2} X_{t-2}+\cdots++\emptyset_{p} X_{t-p}+e_{t}
$$

Keterangan:

$\mu^{\prime}=$ suatu konstanta

$\emptyset_{p}=$ parameter auto regresif ke-p

$e_{t}=$ nilai kesalahan pada saat $\mathrm{t}$

b) Moving Average (MA)

$$
x_{t}=\mu^{g}+e_{t}-\theta_{1} e_{t-1}-\theta_{2} e_{t-2}-\cdots+\theta_{q} e_{t-k}
$$

Keterangan :

$\mu^{r}=$ suatu konstanta

$\theta_{1}$ sampai $\theta_{q}$ adalah parameter-parameter MA

$e_{t-k}=$ nilai kesalahan pada saat $\mathrm{t}-\mathrm{k}$

c) Model Campuran AR dan MA

$x_{t}=\mu^{\prime}+\emptyset_{1} X_{t-1}-e_{t}-\theta_{1} e_{t-1}$

Pada pembentukan model ARIMA yang digunakan dilakukan pengamatan data dengan melihat apakah data yang digunakan sudah berbentuk stasioner atau belum jika data dilakukan pembeda terlebih dahulu. Data dikatakan stasioner jika nilai rata-rata dan varian pada data time series tidak mengalami perubahan yang signifikan pada deret waktu tertentu atau bersifat konstan. Stasioneritas berarti bahwa tidak ada perubahan drastis pada data [12]. Pembeda (Differencing) dilakukan jika data membentuk pola tren dan pola musiman, penentuan dilakukan dengan pengujian akar. Pada penelitian yang menggunakan metode time series, model ARIMA lebih cocok digunakan untuk peramalan berjangka pendek.

\section{Metode Penelitian}

ARIMA adalah metode peramalan yang berdasarkan garis waktu atau data histori yang akan digunakan sebagai acuan peramalan pada masa yang akan datang. Pada metode ARIMA yang dilakukan perlu diperhatikan beberapa hal yaitu data yang digunakan seperti pola yang terbentuk pada data histori, apakah data akan membentuk pola seperti tren atau musiman.

1. Jenis Penelitian 
Penelitian ini adalah penelitian kuantitatif, merujuk pada nilai atau angka dari inflasi yang ada di Indonesia yang akan melakukan peramalan inflasi pada dua tahun berikutnya dengan ARIMA.

2. Objek Penelitian

Penelitian yang dilakukan difokuskan pada penelitian peramalan pada inflasi secara umum yang ada di Indonesia. Data yang digunakan didapat dari situs resmi Badan Pusat Statistik (BPS) yang dapat diunduh secara bebas, data tersebut sama dengan data yang dimiliki Bank Indonesia.

3. Sumber Data

Data yang digunakan dalam penelitian ini adalah data sekunder karena diperoleh melalui pihak lain yaitu Badan Pusat Statistik https://www.bps.go.id/ dan telah diolah menjadi bentuk tabel. Data yang digunakan berjumlah 240 data dari kurun waktu tahun 2000 sampai dengan 2019, seperti di Tabel 1.

Tabel 1. Contoh Data Histori Inflasi

\begin{tabular}{lll}
\hline No & Data & Value \\
\hline 1 & $2000-01$ & 1.32 \\
2 & $2000-02$ & 0.07 \\
3 & $2000-03$ & 0.45 \\
4 & $2000-04$ & 0.56 \\
5 & $2000-05$ & 0.84 \\
6 & $2000-06$ & 0.5 \\
7 & $2000-07$ & 1.28 \\
8 & $2000-08$ & 0.51 \\
9 & $2000-09$ & -0.06 \\
10 & $2000-10$ & 1.16 \\
11 & $2000-11$ & 1.32 \\
12 & $2000-12$ & 1.94 \\
\hline
\end{tabular}

Data inflasi pada tabel 1 dapat dilihat pada website Badan Pusat Statistik dan digunakan secara bebas, data yang diunduh dapat berubah format CSV yang memudahkan dalam pengelolahan dengan data mining. Data yang digunakan sebanyak 240 data dalam bentuk tabel CSV.

Langkah-langkah yang digunakan dalam melakukan penelitian, diantaranya jenis penelitian, sumber data, teknik pengumpulan data, studi literatur, blok diagram dan flowchart serta pengolahan data. Langkah yang dilakukan dalam pembuatan peramalan dengan model yang menggunakan data Time Series ARIMA, yaitu:

1. Pengolahan Data

Pengolahan data dilakukan sesuai tahapan model ARIMA dan menggunakan software Anaconda dengan bahasa pemrograman Python 3. Pengolahan dimulai dari input data pada program,identifikasi data,tahapan identifikasi model ARIMA, dan melakukan peramalan.

2. Perancangan Sistem

Perancangan Sistem dilakukan dalam beberapa tahap yang dijabarkan dengan menggunakan diagram flowchart.

3. Metode

Metode yang digunakan dalam pengelolahan data adalah Auto Regressive Integrated Moving Average (ARIMA). Dalam penggunaan ARIMA dilakukan beberapa tahapan hingga mendapat model yang terbaik dan dapat digunakan sebagai peramalan.

4. Implementasi Sistem

Tahapan ini dilakukan meliputi perancangan sistem yang sudah dibuat dan menghasilkan peramalan yang dilakukan perdasarkan metode yang digunakan.

5. Pengujian Sistem 
Tahapan ini melakukan pengujian peramalan yang dilakukan dengan metode ARIMA dengan menggunakan beberapa indikator yang dapat digunakan sebagai acuan dalam keberhasilan peramalan.

Langkah peramalan dengan data Time Series pada Gambar 1 dimulai dengan memasukan data ke dalam program yang dibuat dengan format CSV. Setelah data berhasil dimasukan maka dilakukan pembuatan plot identifikasi data deret waktu (time series), ACF dan PACF. Setelah berhasil pembuatan plot, dilakukan pengujian stasioner data dengan pengujian unit ADF. Apabila data belum stasioner maka akan dilakukan pembedaan (differencing), tetapi jika data telah stasioner maka dapat dibentuk plot kembali yang sudah stasioner yaitu plot identifikasi ACF dan PACF.

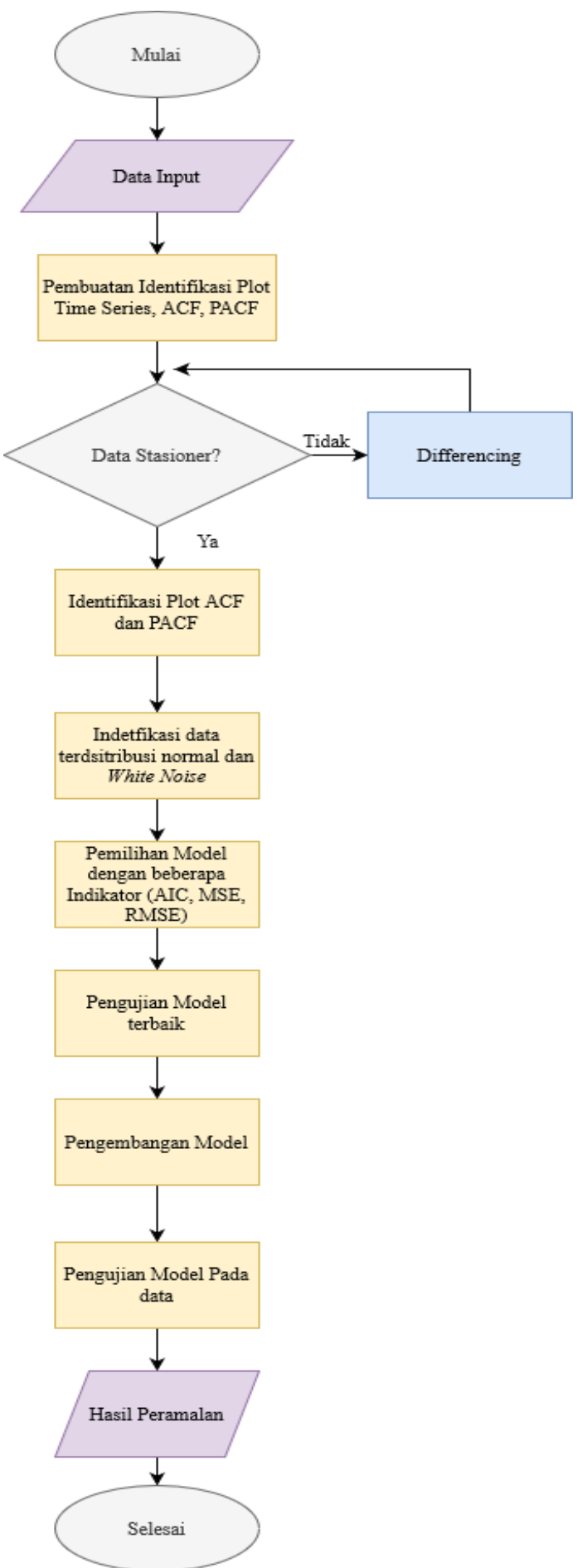

Gambar 1. Langkah Model Peramalan Time Series

http://sistemasi.ftik.unisi.ac.id 
Kemudian dilakukan identifikasi data untuk melihat apakah data terdistribusi dengan normal dan White Noise. Pemilihan model terbaik dilakukan dengan menggunakan beberapa kriteria pemilihan model terbaik dengan melihat nilai AIC, MSE dan RMSE. Model terbaik diuji dengan data yang digunakan. Pengembangan model Auto Regressive Integrated Moving Average (ARIMA) menjadi Seasonal Auto Regressive Integrated Moving Average (SARIMA) pada model sementara yang didapatkan sebelumnya dari model ARIMA (p, d, q) menjadi SARIMA (p, d, q)(P, D, Q)m. Proses terakhir adalah pengujian peramalan dengan model Seasonal-Autoregressive Integrated Moving Average (SARIMA) terbaik.

\section{Hasil dan Pembahasan}

1. Pengujian Stasioner Data

Proses awal sebelum melakukan peramalan adalah mengechek bentuk data apakah sudah sesuai dengan yang diinginkan dalam hal ini data harus stasioner.

\section{ADF Statistic: -10.340298 \\ p-value: 0.000000}

\section{Gambar 2. Penujian ADF}

Dalam pengujian ADF di Gambar 2 menunjukkan hasil bahwa nilai p-value adalah 0.000 dan nilai t-statistic -10.340298 dengan nilai signifikan 0.05 yang berarti data sudah stasioner. Pengujian ini dilakukan untuk mengetahui apakah data yang akan digunakan sudah stasioner atau belum, jika tidak stasioner maka dilakukan namanya pembeda.

4.1. Identifikasi Data dengan menggunakan fungsi Auto Correlation (ACF) dan Partial Auto Correlation (PACF)

Penggunaan Plot ACF dan PACF adalah untuk menentukan nilai dari ARIMA dan dalam pengidentifikasian data apakah data bersifat musiman atau tidak, dapat menggunakan cara ACF dan PACF. Pada grafik ACF dan PACF akan terlihat musiman pada lag yang terdapat pada grafik seperti lag 12, 24, 36. Jika pada lag terjadi kenaikan yang signifikan pada lag-lag tertentu maka dikatakan data bersifat musiman.



Gambar 3. Plot ACF

Pada pengujian yang dilakukan dengan plot ACF di Gambar 3 menunjukkan terjadi lonjakan pada lag pertama yang signifikan dan turun secara perlahan pada lag ke 2 dan 3 sehingga pada kejadian ini menunjukkan adanya dying down karena adanya perubahan secara perlahan pada lag awal 1 sampai 5. 


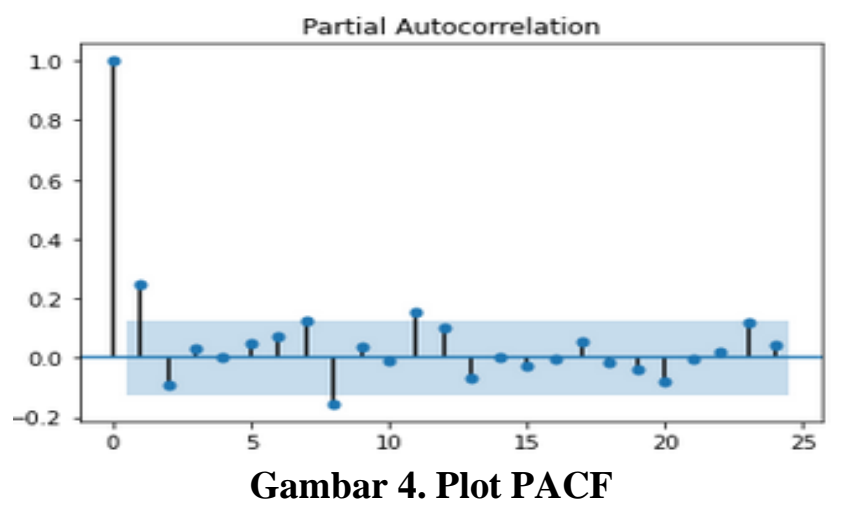

Pada hasil plot PACF pun sama menunjukkan terjadinya dying down pada lag awal yaitu 1 sampai 5 seperti pada plot ACF. Jika pada plot PACF terjadi kenaikan pada lag 12 dan 24. Dengan hasil ACF dan PACF dapat dibentuk dengan model $\mathrm{p}=1$ dan $\mathrm{q}=0$ atau $\mathrm{p}=0$ dan $\mathrm{q}=$ 1 karena terdapat adanya dying down pada lag 1 pada ACF dan PACF. Pada plot di Gambar 4 dapat diidetifikasikan nilai model ARIMA AR dan MA memiliki 3 model bentuk ARIMA (p, d, q) $(1,0,1),(0,0,1),(1,0,0)$.

4.2. Hasil Model Awal ARIMA

Pada pengujian yang dilakukan akan melihat indikator AIC sebagai acuan dimana AIC terkecil yang akan dijadikan dasar pemodelan selanjutnya.

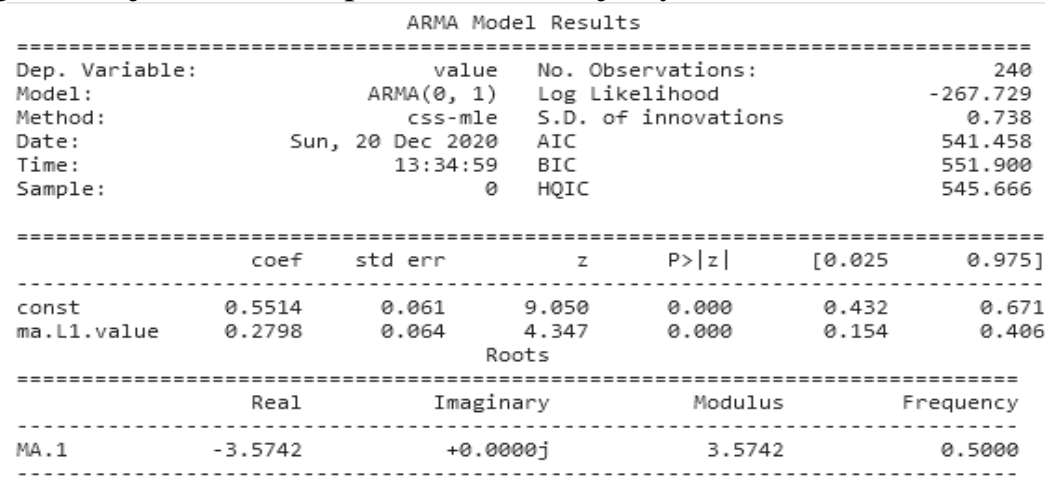

Gambar 5. Model ARIMA $(0,0,1)$

Pada model yang diujikan model ARIMA $(0,0,1)$ di Gambar 5 menghasilkan nilai AIC yang terkecil dibandingkan model yang lain dan memiliki nilai $\mathrm{P}$ yang paling baik yaitu 0.000 dengan tingkat signifikansi 0.05 .

4.3. Pengembangan Model ARIMA

Setelah model dasar didapatkan yaitu dengan model ARIMA $(0,0,1)$ sebagai dasar awalnya, terlihat pada plot PACF pada lag 12 dan 24 lonjakan pola musiman di Gambar 6, berarti data yang digunakan termasuk data musiman yang dapat dimodelkan menjadi ARIMA Musiman. 


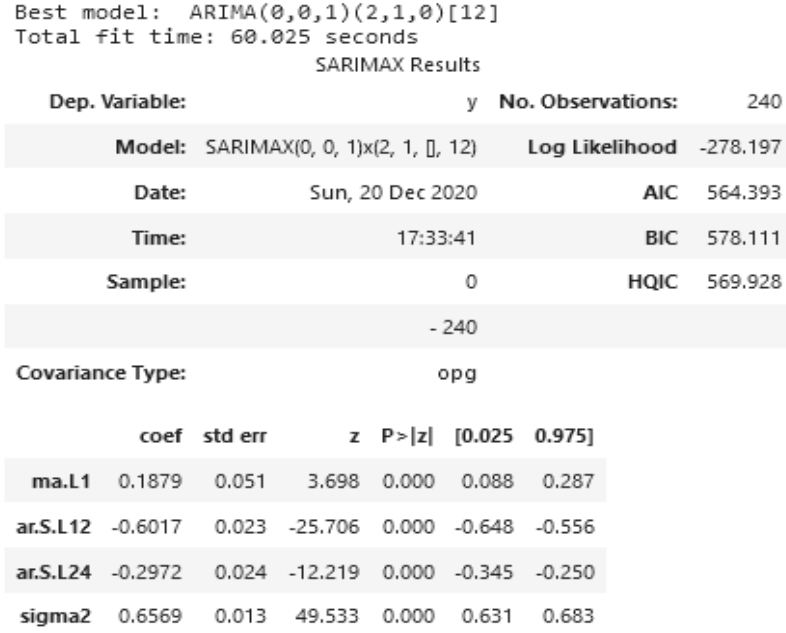

\section{Gambar 6. Pemodelan ARIMA Musiman}

Pada hasil yang didapat bahwa model terbaik yang terbentuk adalah model SARIMA (p, d, q) $(\mathrm{P}, \mathrm{D}, \mathrm{Q}) \mathrm{m}(0,0,1)(2,1,0) 12$. Pada model ini dilakukan difference. Pada model didapat nilai $\mathrm{P}$ menunjukkan data bersifat stasioner karena bernilai lebih dari nilai $\alpha$ yaitu 0,05 . Pada coef MA menunjukkan angka bahwa MA tidak melebih nilai 1 dan pada AIC terbaik didapat dengan nilai 564.393.

4.4. Hasil Grafik Peramalan

Setelah pemodelan selesai dapat dibuat pemodelan visual dengan grafik seperti pada Gambar 7.

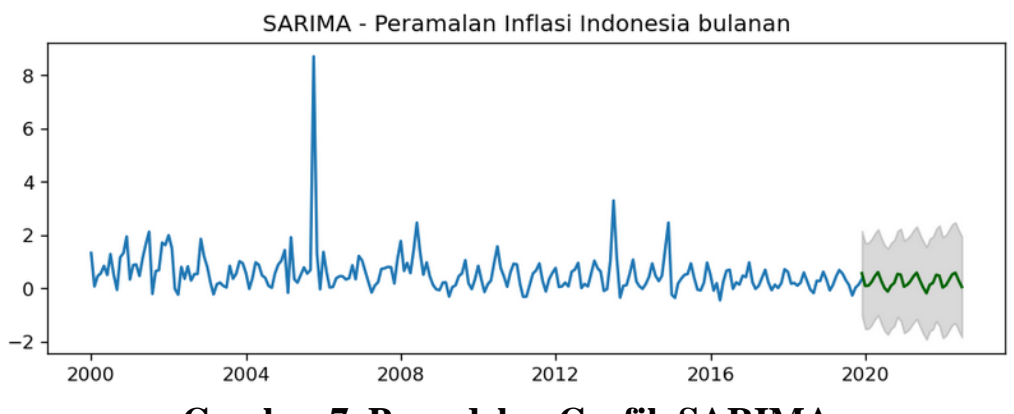

Gambar 7. Pemodelan Grafik SARIMA

Gambar 7 menunjukkan terjadi lonjakan tinggi yang terjadi di antara tahun 2004 dan 2008 lonjakan tersebut terjadi karena nilai inflasi terjadi kenaikan yang sangat signifikan. Pada grafik yang berwarna biru adalah data histori yang digunakan sebagai dataset yang digunakan sedangkan garis berwarna hijau adalah hasil dari peramalan yang menggunakan model SARIMA.

4.5. Hasil Nilai Peramalan

Dalam peramalan yang dilakukan selain dibuat dalam grafik juga mendapatkan dilihat dalam bentuk angka seperti pada Gambar 8. 


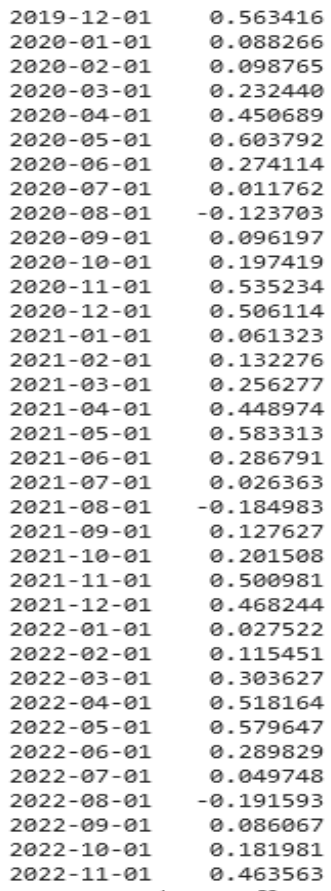

Gambar 8. Hasil Nilai Peramalan SARIMA

Dengan menggunakan model Seasonal-ARIMA dilakukan peramalan dengan model SARIMA (p, d, q), (P, D, Q)m (0, 0, 1), (2, 1, 0)12. Pada model ini menghasilkan nilai AIC terbaik pada pembentukan model yaitu sebesar 564.393 dan pada nilai P setiap model adalah 0.000 yang berarti model dikatakan baik untuk digunakan dalam peramalan. Hal ini menunjukkan model SARIMA dapat digunakan untuk data yang memiliki kategori musiman dan stasioner. Peramalan inflasi Indonesia dapat dilakukan hingga November 2022. Nilai MAPE pada penelitian ini sebesar 4.674266671618802, semakin kecil nilai pada MAPE maka model semakin baik dan AIC 564.393 adalah nilai terkecil di antara model lainnya.

\section{Kesimpulan}

Pada peramalan yang dilakukan didapatkan hasil peramalan inflasi Indonesia dengan interval waktu 36 bulan dari 240 data sejak Januari 2000 hingga Desember 2019. Peramalan ini memberikan hasil untuk kurun waktu akhir tahun 2019 hingga November 2022 (selama 32 periode bulan). Sepanjang tahun 2020 inflasi terbesar pada bulan Mei yaitu sebesar 0.603792, tahun 2021 pada bulan Mei 0.583313 , dan tahun 2022 bulan Mei sebesar 0.579647. Hal ini menunjukkan pola yang dimiliki pada bulan Mei menjadi inflasi terbesar pada setiap tahunnya. Model yang digunakan peramalan adalah SARIMA $(0,0,1),(2,1,0) 12$ dengan nilai AIC 564.393, MAPE 4.888840, dan RMSE 0.59742.

\section{Referensi}

[1] L. N. Zumaidah and A. Soelistyo, "Pengaruh Total Aset, Dana Pihak Ketiga, Dan Kredit Pada Bank Umum Terhadap Pertumbuhan Ekonomi Provinsi-Provinsi Di Indonesia Pada Tahun 2013 -2016," J. Ilmu Ekon., vol. 22, pp. 251-263, 2018.

[2] N. A. Asab, "Inflation Targeting and World Monetary Shocks : Evidence from Developing Economies," vol. 9, no. 3, pp. 140-150, 2020, doi: 10.11648/j.ijber.20200903.17.

[3] M. Feldkircher and P. L. Siklos, "Global inflation dynamics and inflation expectations," Int. Rev. Econ. Financ., vol. 64, no. June, pp. 217-241, 2019, doi: 10.1016/j.iref.2019.06.004.

[4] B. M. A. Abdulrahman, A. Y. A. Ahmed, and A. E. Y. Abdellah, "Forecasting of Sudan Inflation Rates using ARIMA Model," Int. J. Econ. Financ. Issues, vol. 8, no. 3, pp. 17-22, 2018, [Online]. Available: https://www.researchgate.net/publication/325047116\%0D.

[5] C. A. Stephani, A. Suharsono, and Suhartono, "Peramalan Inflasi Nasional Berdasarkan Faktor Ekonomi Makro Menggunakan Pendekatan Time Series Klasik dan ANFIS," Sains Dan Seni ITS, vol. 4, no. 1, pp. 67-72, 2015. 
[6] R. Rismala and R. N. Dayawati, "Prediksi Data Time Series Tingkat Inflasi di Indonesia dengan Menggunakan Differential Evolution," Forecasting, pp. 1-8, 2017, [Online]. Available: http://journals.telkomuniversity.ac.id/knip/article/view/551.

[7] A. J. P. Delima and M. T. Q. Lumintac, "Application of time series analysis for philippines' inflation prediction," Int. J. Recent Technol. Eng., vol. 8, no. 1, pp. 1761-1765, 2019.

[8] I. N. Purnama and P. T. H. Permana, "Perbandingan Peramalan Inflasi Kota Denpasar Menggunakan Metode Fuzzy Time Series Dan Multilayer Perceptron," J. Teknol. Inf. dan Komput., vol. 5, no. 3, pp. 285-296, 2019, doi: 10.36002/jutik.v5i3.801.

[9] O. D. Adubisi, I. J. David, F. E. James, U. E. Awa, and A. J. Terna, "A predictive Autoregressive Integrated Moving Average (ARIMA) Model for Forecasting Inflation Rates," Res. J. Bus. Econ. Manag., vol. 1, no. 1, pp. 1-8, 2018, doi: 10.31248/RJBEM2018.012.

[10] A. M. Al'afi, W. Widiart, D. Kurniasari, and M. Usman, "Peramalan Data Time Series Seasonal Menggunakan Metode Analisis Spektral," J. Siger Mat., vol. 1, no. 1, pp. 10-15, 2020, doi: 10.23960/jsm.v1i1.2484.

[11] I. S. Nurjanah, D. Ruhiat, and D. Andiani, "Implementasi Model Autoregressive Integrated Moving Average (Arima) Untuk Peramalan Jumlah Penumpang Kereta Api Di Pulau Sumatera," TEOREMA Teor. dan Ris. Mat., vol. 3, no. 2, p. 145, 2018, doi: 10.25157/teorema.v3i2.1421.

[12] J. Lusikooy, N. Nainggolan, and J. Titaley, "Prediksi Harga Tutup Saham PT. Garuda Indonesia,Tbk Menggunakan Metode ARIMA," J. MIPA, vol. 6, no. 1, p. 74, 2017, doi: 10.35799/jm.6.1.2017.16174.

[13] J. Rizal and S. Akbar, "Perbandingan Uji Stasioner Data Timeseries Antara Metode : Control Chart, Correlogram, Akar Unit Dickey Fuller, dan Derajat Integrasi," J. Gradien, vol. 11, no. 1, pp. 1040-1046, 2015, [Online]. Available: https://ejournal.unib.ac.id/index.php/gradien/article/view/415.

[14] M. B. Pamungkas, "Aplikasi Metode Arima Box-Jenkins Untuk Meramalkan Kasus Dbd Di Provinsi Jawa Timur," Indones. J. Public Heal., vol. 13, no. 2, p. 183, 2019, doi: 10.20473/ijph.v13i2.2018.183-196.

[15] S. Mirza, S. Mittal, and M. Zaman, "A Review of Data Mining Literature," vol. 14, no. 11, pp. 437-442, 2016. 